\title{
TEACHER AUTONOMY SUPPORT: DOES IT HINDER MOTIVATION AMONG THAI STUDENTS?
}

\author{
${ }^{1}$ Amrita Kaur, ${ }^{2}$ Rosna Awang Hashim \\ \& ${ }^{3}$ Mohammad Noman \\ ${ }^{1,2,3}$ School of Education and Modern Languages, \\ Universiti Utara Malaysia
}

${ }^{1}$ Corresponding author: amrita@uum.edu.my

\begin{abstract}
Purpose - This article examined the relevance of teacher autonomy support [TAS] among Thai students. It is based on a study conducted to compare the effects of TAS on motivation among Thai students. The issue of motivation among Asian students has invited controversy as few cross-cultural relativists have claimed that Asian students get motivated when teachers use controlling strategies.
\end{abstract}

Methodology - The study collected data through a quasiexperimental study with an appended ABA withdrawal design. The subjects were 105 Thai students who completed self-reported questionnaires that assessed perceived autonomy support, intrinsic motivation and self-regulation, before, after and on withdrawal of experiment intervention.

Findings - MANOVA results revealed that students in the experimental group who were in the autonomy supportive teachinglearning environment reported greater interest, effort, relatedness and integrated regulation compared to the control group taught using a traditional approach. Furthermore, students in the experimental group experienced less pressure and reported less external regulation compared to the control group.

Significance - The findings support the claim in Self-determination theory (SDT) that autonomy is not a culturally bound value, and is a pedagogical concept equally relevant to Thai students as it 
facilitates motivation. The findings will encourage Thai educators to adopt autonomy as a pedagogical concept that will help facilitate motivation among their students.

Keywords: teacher autonomy support, motivation, quasi experimental, Thai education reforms, Self-determination theory.

\section{INTRODUCTION}

Self-determination theory (SDT) explains the dynamics of motivation and its quality on the basis of social contextual variables that, if supported, facilitate and maintain high quality motivation. SDT proposes autonomy support as the crucial behavior to be extended by authorities such as teachers, parents, managers and coaches to meet their subordinates' basic psychological need for desirable outcomes (Deci \& Ryan, 2000). The concept of autonomy need satisfaction, when applied to educational settings implies teacher autonomy support (TAS) that is extended by the teacher to learners through classroom contexts (Reeve \& Jang, 2006). In an autonomy supportive classroom, the teacher creates a learning environment that facilitates learners to experience volition and promotes complete endorsement of their actions. However, on the basis of variability in cultural values and practices, the significance of the construct of autonomy has consistently been challenged by cross-cultural researchers. It is often argued that collectivist values that promote conformity within the group diminish the need for autonomy among its associates. In educational settings, critics have claimed that students from eastern cultures experience higher motivation in contexts that emphasize conformity. Controlling strategies have no negative implication on students' motivation. In fact, they progress well under pressure conditions (Iyenger \& Lepper, 1999; Markus \& Kitayama, 1991; 2003). Hence, it is understood that the teachers who are authoritarian and do not value learners' perspective and impose learning might produce beneficial effects for Asian students' motivation.

\section{TEACHER AUTONOMY SUPPORT IN SELF DETERMINATION THEORY}

Autonomy in self-determination theory is defined as actions that are self-endorsed, emanating from self and have internal perceived locus of causality (Ryan \& Deci, 2006). The theory claims that humans 
are naturally motivated to engage in activities that are volitional or self-chosen. In the context of an educational setting, the volitional experience extended by a teacher to the students through the classroom environment is identified as teacher autonomy support. The theory maintains that environments that promote autonomy support contribute significantly towards students learning and academic achievement across cultures.

Reeve and Jang (2006), using a correlation analysis, confirmed a set of instructional behaviors of the teacher that supported autonomy among learners. In an autonomy supportive classroom, the teacher provides the rationale for learning, encourages students to share their opinions, listens carefully, takes students' perspective into consideration, creates flexible seating arrangements for students to have the opportunity to manipulate learning aids, gives enough time for students to work at their own pace, encourages effort and persistence, provides hints to accomplish a task and uses praise as a reward for improvements. An autonomy supportive teacher refrains from using controlling language and giving threatening assessments. Considerable research has provided evidence that when autonomy supportive teachers identify students' needs, preferences and interests, and fulfills them by creating favorable classroom environments, their students in turn, display positive academic outcomes. These included enhanced creativity, greater enjoyment and effort, positive emotions and motivation. (Black \& Deci, 2000; Reeve \& Jang, 2006). However, various cross-cultural researchers (Iyenger \& Lepper, 1999; Iyenger \& DeVoe, 2003; Markus \& Kitayama, 2003) have argued that Asian students do not value autonomy or pursuit of autonomy as it may damage their collectivist values. Such a view has raised the question on whether teaching practices based on contemporary motivation theory will have any significance in eastern cultures.

Nevertheless, proponents of SDT have argued that the concept of autonomy is often misinterpreted (Deci \& Ryan, 2008), for example, it is assumed that the opposite of autonomy is heteronomy, not dependence (Chirkov, Ryan, Kim \& Kaplan, 2003). An individual can rely on others for guidance and still feel autonomous for his actions that are emanating from within (Bao \& Lam, 2008). 
In order to support this proposition, several studies have been conducted to examine the relevance of autonomy in collectivist cultures that confirm the claims made by SDT. For example, Yamauchi and Tanaka (1998) studied fifth-grade Japanese students for their autonomous motivation which was found to be positively related to their self-esteem. In a study of Taiwanese high school students, Hardre et al. (2006) found that autonomy supportive classroom environment was a predictor of better engagement and effort in learning. Another study with South Korean high school students by Jang, Reeve, Ryan and Kim (2009) revealed that students experiencing a high level of autonomy (together with competence and relatedness) reported the most satisfying learning experiences. Zhou, Ma and Deci (2009), in a sample of rural Chinese students from elementary schools found that autonomous motivation has a positive independent relation to perceived competence, interest and perceived choice about schoolwork.

It is abundantly clear from the foregoing review that there are many studies that report the role of teacher autonomy support in teacherstudent classroom interaction. However, not much attention has been given to this issue in Thai society, a society that conforms to collectivist values but promotes autonomy for learners through its education reforms.

\section{Overview: Thailand and Education}

Thailand, a predominantly Buddhist society generates its values from the basic principles of Buddhism that emphasizes tolerance towards others, respect for age, seniority, and hierarchy. Emotions like pomposity, arrogance, conflicts and social display of emotions is highly discouraged in Thai society (Nguyen, 2005). The values generated in Thai society are predominantly focused on respect for hierarchy, humility and polite attitude, and tolerance (Nguyen, 2005; Wallace, 1996). Thai culture places emphasis on respect for hierarchy, reverence for teachers and their position, thus discouraging students from voicing their opinions or questioning in the classroom (Wallace, 1996). Owing to the collectivist values practised in Thailand, Thai education is predominantly teacher-centered and examination oriented. Students are given limited exposure to real life learning and hands-on experiences. Thai classrooms are usually structured, rely on rote memorization skills and have minimal 
class discussions (Pennington, 1999). In order to raise its academic ranking among neighbouring countries and meet the challenges of globalization, the 1999 National Education Act introduced reforms in Thai education. The learning reforms focused on promoting independent or autonomous learning skills among students by creating an environment that will provide opportunities for students to express their opinions, get involved in discussions, and to explore and enjoy learning by doing (Muongmee, 2007). However, it was a challenge to implement the principles and practices of these learning reforms among teachers who were used to chalk and talk methods and who were worried about their traditional dominant role in such a classroom when students are given autonomy (Atagi, 2002; Fry, 2002). Thus, the resultant contradiction of the Thai education system; on the one hand promoting conformity to authority and at the same time proposing reforms that encourage autonomy among students. This paradoxical situation has provided the impetus for this study, which is to investigate the role of teacher autonomy support in motivating Thai students, and the place of TAS in Thai education reforms.

\section{The Present Research}

The primary investigator of this research project had been involved with education in public schools in Thailand for a considerable period of time and has experienced that the polite and calm attitude of Thai students is often misinterpreted by foreign teachers as being passive and uninterested (Chalapati, 2007). The goal of the present research was to investigate the effect of TAS on Thai students' motivation in authentic settings. Using a quasi-experimental design, the purpose was to shed more light on the cross cultural debate surrounding the concept of autonomy. The conceptual framework of this study presents TAS as an independent variable and its effects were observed on a total of seven dependent variables. The variables chosen to measure motivation were consistent with the past literature of SDT on students' motivated learning behavior. (Black $\&$ Deci, 2000). The investigation before intervention confirmed that regular class style was close to controlling type, therefore our first hypothesis was that TAS intervention in the experimental group would predict greater perceived autonomy support, interest, enjoyment, relatedness, and integrated regulation within the classroom in contrast to the control group. Similarly, it was expected 
that the TAS intervention would predict less pressure and less external regulation as compared to the control group. Furthermore, through the second hypothesis we expected that on withdrawal of the TAS intervention, the experimental group will show significant decrease in mean for perceived autonomy support, interest and enjoyment relatedness and integrated regulation, and a significant increase in pressure and external regulation. A correlational analysis was conducted to test the third hypothesis where the anticipation was a positive relationship between students' perceived autonomy support (PAS) with all the variables except pressure and external regulation. In the fourth hypothesis, in light of the SDT literature that does not propose teacher autonomy support effectiveness for a specific gender, however, a 2x2 factorial MANOVA was performed to see if significant mean differences between pretest and posttest 1 of experimental and control group occurred as a result of any gender interaction between groups

\section{METHODOLOGY}

\section{Participants}

A total of 103 Thai students, forty seven boys (45.6\%) and fifty six girls $(54.3 \%)$ participated in the study. The participants came from two sections of grade 6 of a Thai public school. The students' ages ranged from 11 to 13 years. The demographic data reported 99.8\% were ethnic Thai and belonged to the lower middle SES. The participation in responding to the questionnaire was voluntary; however, all the students chose to participate since the data was collected during regular English classes.

\section{Procedure}

The Nonequivalent Control Group Design (NEGD) (Ary, Jacobs, \& Razavieh, 2005) with single subject A-B-A (treatment withdrawal for posttest2) was incorporated to have a robust methodology. Throughout the research procedure, internal and external validity threats were addressed in an appropriate way. Three questionnaires were prepared with slight variation in tenses for pretest, posttest1 and posttest 2 to measure the variables. The questionnaires were administered by the school coordinator at the end of each class. 
The school had six sections of Grade six. Each section took the pretest and provided the demographic information. The two sections that matched on demographic and pretest data were selected for the study. Demographic data and MANOVA analysis of pretest data provided evidence to establish both the groups as homogenous. The omnibus multivariate results presented no significant difference between the two groups (Wilks' $\lambda=.98, \mathrm{~F}(7,95)=.22, \mathrm{p}=.98$ ). Teachers of both the classes responded to the personality orientation and motivating styles scale. The teacher who scored higher on these scales was considered appropriate for delivering the TAS intervention to the experimental group (Reeve, 1998). On the basis of selection of the teachers, the two classes were divided into two groups, the experimental ( 23 boys and 28 girls) and the control group ( 24 boys and 28 girls). Students in both the groups were kept uninformed of the experiment to control the internal validity threat of subject effect.

The teacher for the experimental group underwent three intensive sessions of training in conducting the intervention. Each session lasted for approximately 60-80 minutes. The training format, contents and delivery modes were similar to that of Reeve, Jang, Carrell, Jeon \& Barch (2004). The teacher was duly observed and measured for internalizing TAS as a teaching practice.

An intensive teaching module on the classroom practice of TAS was adapted from a study conducted by Reeve et al. (2004) and the motivating styles were also adapted from the previous studies that focused on TAS instruction-based methodology (Reeve, Bolt \& Cai, 1999; Reeve 2006; Reeve \& Jang, 2006). The TAS intervention instructions were embedded in the regular lesson plan, and this involved the teacher creating seating arrangements that gave flexibility to students in manipulating aids and interacting with classmates, inviting students' opinion on learning topics and acknowledging their respective perspectives. When the topic was difficult or uninteresting for students, the teacher would assist students with support materials, gave them rationales for pursuing uninteresting topic, facilitated students' learning by giving positive feedback and letting students work at their preferred pace. The teachers also carried out non-threatening assessment procedures. 
The students in the experimental group underwent autonomy supportive intervention for seven sessions (60 minutes each) in a regular classroom setting, whereas students in the control group were taught using the traditional methodology. The intervention period was stretched considerably so that students had sufficient time to get over the novelty factor. On completion of the intervention, both the groups responded to posttest 1 . The intervention was withdrawn from the experimental group and both the groups were exposed to English language lessons in a traditional way for the next four sessions. Subsequently, both the groups responded to posttest 2 . The school's coordinator administered all the tests at the end of the English language class. Teachers in both the classes were observed regularly to establish consistency and accuracy in intervention and withdrawal procedure.

\section{Measurements}

The scales used for the present study aimed to measure students' motivation by assessing their classroom experiences of learning English and quality of interaction with the teacher. The questionnaires were used in their original language, i.e., English, but were slightly adapted in terms of language for the different experimental conditions. A pilot study was conducted to check the reliability, validity, content validity and suitability of the instruments in terms of the format of the questionnaire, wording, and ability to use Likert type scale by students. The measure of Cronbach alpha was used to assess internal consistency and reliability of all the instruments.

General Information Questionnaire for Students: Participants reported their age, gender, race, family income, parent's education, number of years of learning the English language, attendance at weekend or evening classes and recent National Test scores in this questionnaire.

Learning Climate Questionnaire (LCQ): A short six-item version LCQ developed by Deci, Connell and Ryan (1989) was used to assess the degree to which the students perceive their teachers to be autonomy supportive (e.g., 'I feel that my teacher provides me with choices'). The alpha coefficient of internal consistency was consistent with past researches (pretest $\alpha=.92$; posttest1 $\alpha=.90$; posttest $2 \alpha=.92$ ). The items were rated on a 7-point response scale ( $1=$ not at all true to $7=$ very much true). 
Intrinsic Motivation Inventory (IMI): Four subscales of this inventory were used separately like in many studies (Deci, Egahari, Patrick \& Leone, 1994; Ryan, Connell \& Plant, 1990) on a 7-point scale $(1=$ not at all true to $7=$ very much true) to assess student's interest ( e.g., 'I enjoyed learning English'), effort (e.g., 'I put a lot of effort to do this'), pressure (e.g., 'I felt very tensed while learning English') and relatedness (e.g., 'I felt very close to my teacher'). Validity of IMI has been examined by McAuley, Duncan and Tammen (1989). Items were slightly rephrased. The Alpha coefficient for these subscales ranged from .89 to.93.

Self-regulation Questionnaire-Academics (SRQ-A): Two slightly adapted subscales of the SRQ-A questionnaire developed by Ryan $\&$ Connell (1989) were used. In the context of this study, items were slightly rephrased for external regulation (e.g., "why do I learn English?' response 'because I will get into trouble') and integrated regulation (e.g., 'Why do I learn English?' 'Because I want to understand the subject'). Students responded on a 7-point scale ( $1=$ not at all true to $7=$ very much true). Alpha reported for this scale was pretest $\alpha=.90$, posttest $1 \alpha=.80$, and posttest $2 \alpha=90$.

\section{RESULTS AND DISCUSSION}

Four hypotheses were developed for the present study that are discussed in this section.

Hypothesis 1: There will be a significant mean difference between experimental and control group in perceived autonomy support, interest, enjoyment, relatedness, pressure and external and integrated regulation after the intervention.

Multivariate analysis of variance (MANOVA) was used as the main analysis to study group difference after pretest, posttest 1 and posttest 2 between and within the experimental and control groups on total of seven variables. Multivariate results presented no significant difference (Wilks' $\lambda=.98, \mathrm{~F}(7,95)=.02, \mathrm{p}=.98$ ) between the two groups on all seven variables at pretest level. However, after the intervention, the two groups revealed a significant difference (Wilks' $\lambda=.13, \mathrm{~F}(7,95)=90.58, \mathrm{p}=.001, \eta 2=.87$ ) on posttest 1 . Univariate analysis, as shown in Table 1 , showed the main effects on all variables. 
Table 1

Descriptive Statistics and Univariate results on posttest 1

\begin{tabular}{lcrrrrr}
\hline & \multicolumn{2}{c}{ Experimental } & \multicolumn{2}{c}{ Control } & \multicolumn{2}{c}{ MANOVA Results } \\
\hline & $\mathrm{M}$ & $\mathrm{SD}$ & $\mathrm{M}$ & $\mathrm{SD}$ & $\mathrm{F}$ & $\eta 2$ \\
\hline Interest & 5.50 & 1.13 & 2.35 & 1.30 & $162.86 * *$ & .61 \\
Effort & 5.50 & 1.20 & 2.46 & 1.23 & $181.72 * *$ & .64 \\
Pressure & 2.52 & .86 & 5.30 & 1.50 & $124.14 * *$ & .55 \\
Relatedness & 5.40 & 1.00 & 2.15 & .95 & $254.09 * *$ & .71 \\
PAS & 5.50 & .90 & 2.00 & 1.30 & $326.57 * *$ & .76 \\
External & 2.81 & 1.24 & 5.31 & 1.00 & $116.91 * *$ & .53 \\
Integrated & 5.52 & 1.41 & 2.80 & 1.51 & $77.18 * *$ & .43 \\
\hline
\end{tabular}

${ }^{\text {a }}$ Experimental group $\mathrm{n}=51$ Control group $\mathrm{n}=52$

$* * \mathrm{p}<.007$ (adjusted alpha as per Bonferroni procedure)

Hypothesis 2: There will be a significant difference in means for perceived autonomy support, interest, enjoyment, pressure, relatedness and external and integrated regulation on withdrawal of the TAS intervention in experimental group.

After the withdrawal of the treatment in the experimental group, MANOVA analysis revealed significant omnibus effect (Wilks' $\lambda=.10, \mathrm{~F}(7,44)=54.71, \mathrm{p}=.001)$, but univariate failed to show significant difference on the variables: interest, pressure, external and integrated regulation. Given the significance of the overall test, the univariate main effects were examined and they are as shown in Table 2 below.

Table 2

Descriptive Statistics and Univariate results on posttest 2

\begin{tabular}{llcrrr}
\hline & Dependent Variables & M & SD & F & $\eta 2$ \\
\hline Experimental & Interest & 5.10 & 1.01 & 2.01 & .03 \\
Group & Effort & 4.81 & 1.34 & 9.47 & .15 \\
& Pressure & 3.03 & 1.50 & 7.86 & .13 \\
& Relatedness & 4.35 & 1.35 & 15.15 & .23 \\
& PAS & 4.43 & .97 & 36.19 & .42 \\
& External & 2.70 & 1.04 & .33 & .00 \\
& Integrated & 5.51 & .93 & .01 & .00 \\
\hline
\end{tabular}

$\mathrm{n}=51$; PAS: Perceived autonomy support

$* \mathrm{p}<.007$ (adjusted alpha as per Bonferroni procedure) 
Hypothesis 3: Perceived autonomy support (PAS) will be positively correlated with interest, enjoyment, relatedness and integrated regulation and negatively correlated with pressure and external regulation.

Correlations between PAS and each variable are as presented in Table 3. Variable interest showed a significant positive correlation with PAS at pretest $(\mathrm{r}=.41, \mathrm{p}<.05)$, postest $1(\mathrm{r}=.74, \mathrm{p}<.05)$ and posttest2 $(\mathrm{r}=.82, \mathrm{p}<.05)$. Variable effort's positive correlation with PAS was significant at postest $1(\mathrm{r}=.81, \mathrm{p}<.05)$ and postest $2(\mathrm{r}-.77$, $\mathrm{p}<.05)$, however, at pretest the correlation was positive but found to be non-significant $(\mathrm{r}=.18, \mathrm{p}<.05)$. Variable pressure consistently showed significant negative correlation at pretest $(r=-.37$, $\mathrm{p}<.05)$, posttest $1(\mathrm{r}=-.64, \mathrm{p}<.05)$ and posttest $2(\mathrm{r}=-.48, \mathrm{p}<.05)$. Relatedness was significantly positively correlated with TAS in pretest $(\mathrm{r}=.35, \mathrm{p}<.05)$, posttest $1(\mathrm{r}=.89, \mathrm{p}<.05)$, and posttest $2(\mathrm{r}=.75$, $\mathrm{p}<.05)$. External regulation was found to be significantly negatively correlated with PAS in pretest $(\mathrm{r}=-.33, \mathrm{p}<.05)$, posttest $1(\mathrm{r}=-.76$, $\mathrm{p}<.05)$, and posttest $2(\mathrm{r}=-.65, \mathrm{p}<.05)$. Integrated regulation showed significant positive correlation with PAS at pretest $(\mathrm{r}=.41, \mathrm{p}<.05)$, postest $1(\mathrm{r}=.79, \mathrm{p}<.05)$ and posttest $2(\mathrm{r}=.79, \mathrm{p}<.05)$.

Table 3

Correlation Between all Variables with Perceived Autonomy Support at Pretest, Posttest 1 and Postest 2

\begin{tabular}{lccc}
\hline PAS /Variables & $\begin{array}{c}\text { No treatment } \\
\text { Pretest }\end{array}$ & $\begin{array}{c}\text { Treatment } \\
\text { Postest 1 }\end{array}$ & $\begin{array}{c}\text { Withdrawal } \\
\text { Postest 2 }\end{array}$ \\
\hline Interest & $.41^{*}$ & $.74^{*}$ & $.82^{*}$ \\
Effort & .18 & $.81^{*}$ & $.77^{*}$ \\
Pressure & $-.37^{*}$ & $-.64^{*}$ &.$-48^{*}$ \\
Relatedness & $.35^{*}$ & $.89^{*}$ & $.75^{*}$ \\
External & $-.33^{*}$ & $-.76^{*}$ & $-.65^{*}$ \\
Integrated & $.41^{*}$ & $.79^{*}$ & $.79^{*}$ \\
\hline$*$ p $<.05$ & & &
\end{tabular}

Hypothesis 4: There is no significant interaction between the effects of TAS and gender in the experimental group.

A 2x2 factorial MANOVA was performed to examine interaction between TAS effects and gender. The analysis revealed that there was no significant interaction between TAS effects and gender 
(Wilks' $\lambda=.841, \mathrm{~F}=(7,43)=1.15, \mathrm{p}=.346)$ in experimental group. Therefore, it can be concluded that the significant mean differences did not occur as a result of gender.

In general, it is observed that students have the ability to decipher the difference between social contexts that are controlling or autonomy supportive (Reeve \& Jang, 2006). Hence, students in both the groups reported a lower perception of autonomy support at pre-test, whereas the experimental group reported a significantly higher perception of autonomy support after the intervention as compared to the control group. Similarly, when the autonomy support was withdrawn, students of the experimental group reported a significantly lower perception of autonomy support in posttest 2 .

Students in both the experimental and control groups reported a lack of interest in the pretest owing to the classroom environment being less flexible, more controlling and did not facilitate positive and active interaction with the environment (Reeve \& Jang, 2006). However, in experimental conditions (with TAS), students reported a higher level of interest in the posttest 1 for English lessons. Contrary to our assumption, students did not report a significant decrease in mean for the variable 'interest' in the treatment withdrawal condition. On the basis of the literature on the developmental phases and types of interest (Hidi \& Renninger, 2006), we assumed that the prior experience of students learning English lessons in an autonomy supportive environment was considered responsible for triggering a prolonged state of interest. Students in the experimental group showed a significant increase in their effort from pretest (without TAS) to posttest1 (with TAS) condition. It is likely that during the TAS treatment, when the teacher provided hints, gave positive feedback and praised students, the students tried hard and focused attention to accomplish their task or learn the lesson. Moreover, TAS practices do not limit the opportunities for students to exert effort; it is an interactive process that motivates students in expending efforts in more than one way. Therefore, when the TAS was withdrawn, students reported significantly less effort as compared to their level of effort in autonomy supportive conditions.

In the autonomy supportive classroom when a teacher is more flexible, refrains from using controlling language and setting 
deadlines, does not utter directives or gives threatening evaluation, he/she is able to create a more relaxed environment for learners to have a better academic outcome since children are capable of distinguishing between autonomy support and controlling behaviors of the teacher (Assor, Kaplan, \& Roth, 2002). As a result, students in the experimental group reported significantly less pressure in posttest 1 as compared to the pretest. Consistent with empirical beliefs, students in the experimental group reported feeling more pressured in posttest 2 as compared to posttest 1, however, the increase was not significant. Emotion theorists have long argued that emotions, specifically the emotion of interest plays a significant role in the process of learning (Weiss \& Beal, 2005). It is emphasized that affective variables are coherently interconnected with each other. Therefore, a task that heightens emotion of interest is likely to lessen the feeling of pressure among learners and vice versa.

Relatedness is said to develop and flourish in a classroom context that facilitates autonomy support by acknowledging the student's perspective, provides opportunities for initiative, and provides choice (Miserandino, 1996). Therefore, students reported greater relatedness in TAS conditions and a significant decrease when TAS was withdrawn. These findings have shown the unfounded basis of the cross-cultural perspective that suggests that pursuit of autonomy inhibits relationship building in a society where personal bonds are valued and being unique is discouraged (Bao \& Lam, 2008) Instead, it was observed that when a teacher was considerate, respected students' perspective and did not issue directives, students felt connected and were able to identify with the teacher's goal. These conditions had enabled the students to perform well academically.

External regulation and integrated regulation were the two extreme regulatory styles that were examined in the present study because their characteristics were identifiable with students learning process and school functioning. Developing self-regulation of an activity in school context is beneficial for better school functioning and learning outcomes, especially when the contents taught are not interesting enough (Ryan \& Deci, 2002). The development of various stages of self-regulation is largely dependent on the environmental and social contextual factors (Ryan \& Deci, 2006). Therefore, it is understood 
that an autonomy supportive environment promotes a better form of regulation (integrated) and a controlling environment promotes a weaker form of regulation (external). Consistent with this belief, students in the experimental group showed a significant increase in integrated regulation and a significant decrease in external regulation after the autonomy support intervention. However, on withdrawal of the intervention of TAS from the experimental group, students did not report any significant difference on the external or integrated regulation scale.

A deeper scrutiny of the literature relevant to self-regulation reveals that when individuals regulate their behaviors as a reaction to their environment, they tend to assimilate those values within their personality and learn to identify with them. Self- regulation is a process through which non-intrinsically motivated behavior may turn into intrinsically motivated one (Ryan \& Deci, 2006). Moreover, it suggests that this change develops through stages and comes into effect over a period of time (Ryan \& Deci, 2000). As was in the case of the present study, when students were exposed to an autonomy supportive environment, they were facilitated towards changing their regulation style to a stronger one for self-determined actions. By comparing the findings of posttest 1 with pretest on both the kinds of regulation, it became evident that the teacher was able to convince students that learning in class, doing homework or making effort can harmoniously co-exist with the student's personal interest. It was likely that by the time the intervention period ended, students had integrated and assimilated the value for learning in that class. Therefore, they failed to show any difference upon the withdrawal of intervention.

Similar to the cross cultural controversy over the relevance of SDT theory, many researchers have challenged the relevance of the theory on the basis of gender (Iyengar \& DeVoe, 2003; Jordon, 1997). They have postulated that autonomy is primarily a male concept and is not relevant for females' psychological functioning. The results for gender interaction in the experimental group were non-significant. Also, the mean difference between the experimental and control groups on the basis of gender was found to be non-significant. Boys and girls had similar means on perceived autonomy support, they reported similar 'interest' experience and were equally sensitive to TAS when showing effort in learning. Similarly, both the genders 
reported negative emotions of anxiety and pressure in equal magnitude. There was no significant difference between genders on forming a relationship bond with the teacher and there were similar findings for regulation techniques. This reiterates the claim by SDT that culturally defined values are easily internalized by individuals and they facilitate in making actions self-determined.

The general belief among educators is that Asian students do not have any ideas on how to exercise autonomy in their personal and academic lives. This leads to culturally laden teaching methodologies by several foreign and local educators among schools in Asia which undermine the students need for autonomy (Littlewood, 1999). The findings of the present study provide further evidence for the significance of autonomy support and its academic benefits in Asian classroom settings. If teachers create a dynamic class environment and let students work in accordance with their emerging interest and integrated value, teachers can help their students fulfill their need for autonomy, thus producing self-determined actions. It is evident from this study that the learning motivation of Thai students increases when they perceive their learning context as autonomy supportive and flexible. Students reported higher interest, greater effort, better relatedness and less pressure in autonomy supportive classroom settings. They were also better able to identify with school values. Therefore, the value of autonomy was proven to be equally critical for Thai students' motivation as it is for students in western cultures.

\section{CONCLUSION}

It is a point often stressed by cross-cultural researchers that hierarchical respect, conformity, and social harmony are essential to a collectivist society. However, such a view may lead to a misinterpretation of the concept of autonomy in the classroom context and teachers in the Asian classroom continue to rely more on controlling teaching strategies. The present study is an attempt to elucidate the meaning of autonomy support and its practices in real classroom settings. The overall results seem to suggest that teacher autonomy support play an important part in the learning motivation of students from a collectivist society. 
The treatment procedure of the present study provides a framework of TAS as a student centered pedagogy and provides the necessary support for teachers to expand their motivating styles. However, replications of this design would be required to further refine the ways to apply TAS as a part of the regular teaching style or to incorporate autonomy supportive styles in the basic school curriculum. Replication of the present study with samples of different ages and different cultural backgrounds would provide more support for the claim in self-determination theory that autonomy support is universally beneficial for all individuals. Further research, keeping the limitations of the self-report measure in mind, may study the effects of TAS on students' motivation using qualitative data from multiple sources of information. These would have to include student and teacher interviews, class observations on student participation and focus group input after intervention in order to gain a deeper insight into the effects of intervention.

\section{REFERENCES}

Ary, D., Jacobs, L. C., \& Razavieh, A. (2005). Introduction to research in education (7th ed). Wadsworth: Thomson learning.

Assor, A., Kaplan, H., \& Roth, G. (2002). Choice is good, but relevance is excellent: Autonomy-enhancing and suppressing teacher behaviours in predicting student's engagement in school work. British Journal of Educational Psychology, 72, 261-278.

Atagi, R. (2002). Thailand education reform project. School reform policy, final report. ADB TA 3585 THA. Retrieved from http://www.worldedreform.com

Bao, X., \& Lam, S. (2008). Who makes the choice? Rethinking the role of autonomy and relatedness in Chinese children's motivation. Child Development, 79, 269-283.

Black, A. E., \& Deci, E. L. (2000). The effects of instructors' autonomy support and students' autonomous motivation on learning organic chemistry: A self-determination theory perspective. Science Education, 84, 740-756.

Deci, E. L., Connell, J. P., \& Ryan, R. M. (1989). Self-determination in a work organization. Journal of Applied Psychology, 74, 580-590. 
Deci, E. L., Eghrari, H., Patrick, B. C., \& Leone, D. (1994). Facilitating internalization: The self-determination theory perspective. Journal of Personality, 62, 119-142.

Deci, E. L., \& Ryan, R. M. (2008). Facilitating optimal motivation and psychological well-being across life's domains. Canadian Psychology, 49, 14-23.

Deci, E. L., \& Ryan, R. M. (2000). The "what" and "why" of goal pursuits: Human needs and the self-determination of behaviour. Psychological Inquiry, 11, 227-268.

Chalapati, S.( 2007b). The internationalisation of higher education in Thailand: case studies of two English-medium business graduate programs (Unpublished doctoral dissertation). Retrieved from http://researchbank.rmit.edu.

Chirkov, V. I., Ryan, R. M., Kim, Y., \& Kaplan, U. (2003). Differentiating autonomy from individualism and independence: A self-determination theory perspective on internalization of cultural orientations and well-being. Journal of Personality and Social Psychology, 84, 97-110.

Fry. G. W. (2002).Synthesis Report: From crisis to opportunity, the challenges of educational reform in Thailand. Report for the Office of the National Education Commission and the Asian Development Bank (TA 3585-THA).

Hardré, P. L., Chen, C. H., Huang, S. H., Chiang, C.T., Jen, F. L., \& Warden, L. (2006). Factors affecting High School Student's Academic Motivation in Taiwan. Asia Pacific Journal of Education, 26(2), 189-207.

Hidi, S., \& Renninger, K. A. (2006). The four-phase model of interest development. Educational Psychologist, 41(2), 111-127.

Iyengar, S. S., \& De Voe, S. E. (2003). Rethinking the value of choice: A cultural perspective on intrinsic motivation. In V.Murphy - Berman \& J. J. Berman (Eds), Nebraska Symposium on Motivation: Cross-cultural differences in perspective on self (Vol. 49, pp. 129-174). Lincoln: University of Nebraska Press.

Iyengar, S. S., \& Lepper, M. R. (1999). Rethinking the value of choice: A cultural perspective on intrinsic motivation. Journal of Personality and Social Psychology, 76, 349-366.

Jang, H., Reeve, J., Ryan, R. M., \& Kim, A. (2009). Can selfdetermination theory explain what underlies the productive, satisfying learning experiences of collectivistically-oriented Korean adolescents? Journal of Educational Psychology, 101, 644-661. 
Jordon, J. V. (1997). Do you believe that the concepts of self and autonomy are useful in understanding women? In J.V. Jordon (Ed), women's growth in diversity, (pp. 29-32). New York: The Guilford Press.

Littlewood, W. (1999). Defining and developing autonomy in East Asian contexts. Applied Linguistics, 20, 1, 71-94.

Markus, H. R., \& Kitayama, S. K. (2003). Models of agency: Sociocultural diversity in the construction of action. In V. Murphy-Berman \& J. J. Berman (Eds.), Nebraska Symposium on Motivation: Vol. 49. Cross cultural differences in perspectives on the self (pp. 1-57). Lincoln, NE: University of Nebraska Press.

Markus, H. R., \& Kitayama, S. (1991). Culture and the self: Implications for cognition, emotion, and motivation. Psychological Review, 92, 224-253.

McAuley, E. Duncun, T. \& Tammen, V. V. (1989). Psychometric properties of the intrinsic motivation inventory in a competitive sport setting: A confirmatory factor analysis. Research Quarterly for Exercise and Sports, 60(1), 48-58.

Miserandino, M. (1996). Children who do well in school: Individual differences in perceived competence and autonomy in aboveaverage children. Journal of Educational Psychology, 88, 203-214.

Muongmee, S. (2007). The role of lifelong learning and self-directed learning in educational reform in Thailand. Educational Journal of Thailand, 33(1), 1 January-December 2007.

Nguyen, T. H. (2005). Cultural background for ESL/EFL teachers cuyahoga community college. Paper appeared in a multicultural project at Northeast ABLE Resource Center (Ohio).

Pennington, M., (1999). Asia takes a crash course in educational reform. Retrieved from http://www.unesco.org

Reeve, J. (1998). Autonomy support as an interpersonal motivating style: Is it teachable? Contemporary Educational Psychology, 23, 312-330.

Reeve, J. (2006). Teachers as facilitators: What autonomy-supportive teachers do and why their students benefit. Elementary School Journal, 106, 225-236.

Reeve, J., Bolt, E., \& Cai, Y. (1999). Autonomy-supportive teachers: How they teach and motivate students. Journal of Educational Psychology, 91, 537-548. 
Reeve, J., Jang, H., Carrell, D., Jeon, S., \& Barch, J. (2004). Enhancing students' engagement by increasing teachers' autonomy support. Motivation and Emotion, 28, 147-169.

Reeve, J. \& Jang, H. (2006). What teachers say and do to support students' autonomy during a learning activity. Journal of Educational Psychology, 98, 209-218.

Ryan, R. M., \& Connell, J. P. (1989). Perceived locus of causality and internalization: Examining reasons for acting in two domains. Journal of Personality and Social Psychology, 57, 749-761.

Ryan, R. M., Connell, J. P., \& Plant, R. W. (1990). Emotions in nondirected text learning. Learning and Individual Differences, 2, 1-17.

Ryan, R. M., \& Deci, E. L. (2000). Intrinsic and extrinsic motivations: Classic definitions and new directions. Contemporary Educational Psychology, 25, 54-67.

Ryan, R. M., \& Deci, E. L. (2002). An overview of self-determination theory. In E. L. Deci \& R. M. Ryan (Eds.), Handbook of selfdetermination research (pp. 3-33). Rochester, NY: University of Rochester Press.

Ryan, R. M., \& Deci, E. L. (2006). Self-regulation and the problem of human autonomy: Does psychology need choice, selfdetermination, and will? Journal of Personality, 74, 15571586.

Wallace, M. (1996, October) Traditional cultural themes in the hearts of today's Northern Thai youth. Proceedings of the Sixth International Conference on Thai Studies: Theme III (pp. 201-212). Chiangmai University Thailand.

Weiss, H. M., \& Beal, D. J. (2005). Reflections on affective events theory. In N. M. Ashkanasy, W. J. Zerbe, \& C. E. Hrtel (Eds.), Research on emotions in organizations: The effect of affect in organizational settings (vol. 1, pp. 1-21). UK: Elsevier, Ltd.

Yamauchi, H., \& Tanaka, K. (1998). Relations of autonomy, selfreferenced beliefs and self-regulated learning among Japanese children. Psychological Reports, 82, 803-816.

Zhou, M., Ma, W. J., \& Deci, E. L. (2009). The importance of autonomy for rural Chinese children's motivation for learning. Learning and Individual Differences, 19, 492-498. 